\title{
Analytic Practical Theory of Education and German Critical Pädagogik: Comparing Their Critical Dimension
}

\author{
Flora Liuying $\mathrm{Wei}^{1}$ \\ Published online: 23 November 2019 \\ (c) The Author(s) 2019
}

\begin{abstract}
Two critical theories-both contemporaneous and complementary-in Western philosophy of education spanning the 1960s to the 1980s will first be explicated, and then their significant intellectual values will be discussed on the basis of such a comparative account. These two critical models are the practical theory of education in the Anglophone world (typically in the UK) and the critical theory of education in the Continental Germany. I will introduce them-namely, analytic practical educational theory and German critical pädagogik - one after another, by focusing on their complementary differences, involving characteristic rationalities, typical forms of criticism, corresponding ways of exercising criticalities, and frames of reference regarding the sources of their criticalities. Based on such distinctions and contrasts, I will in the final section argue for their inherent value of coexistence, their practical value in illustrating the unique construction of academic educational studies which has respectively developed in the Anglo-American world and in the Continental world. As an additional point about their epistemic value to understand educational knowledge and scholarship accumulated in the West, I will further argue that these two philosophical-critical theories of education in parallel constitute peak academic experiences. This is mainly because they are compelling evidence, demonstrating how differently yet legitimately the two camps of Western educational scholarships deal with the same issue of criticality in contrasting yet complementary ways.
\end{abstract}

Keywords Analytic practical educational theory · German critical pädagogik · Anglophone foundational construction of educational studies - Continental autonomous construction of educational studies

\section{Introduction}

The prosperity of educational theory is deeply connected with the expansion of mass education and the elevation of teacher education when reviewing the overall history of education in the West (Tröhler 2013, p. 57; Horlacher 2015, p. 5). Similarly, the issue of educational theory has also become an exciting centre of interest for the Chinese as its enterprise

Flora Liuying Wei

1.wei.1@research.gla.ac.uk; flora_liuyingwei@163.com

1 University of Glasgow, St Andrews Building, 11 Eldon Street, Glasgow G3 6NH, UK 
of public education was carried out substantially within the past century. And this ascending quest for educational theory is far from its end, at least in current China: the prominent movement calling for realistic educational research or empirical sciences of education was just announced in January 2017, gathering around 32 related institutes of education all over China to strengthen the scientific study of education (see ECNU Manifesto of the positivist educational research), meanwhile 'philosophy of education' has been coined as a core course in the country's new teacher education (see Document Teacher [2011]6, Ministry of Education of the People's Republic of China). Furthermore, two international educational journals-the ECNU Review of Education $(R O E)^{1}$ by the East China Normal University and the Beijing International Review of Education $(B I R E)^{2}$ by the Beijing Normal University-have recently been established in China while published in English. It writes clearly in their scopes that both conceptual and empirical works in education are encouraged. Anyway, in an age when the practice of modern education is popular, robust educational theories, be they speculative or scientific, are certainly highly expected and will continue to be important.

On the other hand, regarding what educational theory is, what are the nature and function of theory, and its relationship with practice, etc. there have already been contentious discussions in the field. For example, in accordance with the analytic philosophers of education, there are at least four kinds of foundational educational theory: philosophy of education, sociology of education, psychology of education, and history of education (Tibble 1966; Hirst 1983). Surely there are other promising theories which come from neuroscience and big-data analyses when applied in education. However, as in the Chinese context depicted above where various kinds of educational theory are relatively equally encouraging, this paper will pay its attention to the philosophical style of theory of education.

According to Hou's (2011) systematic examination of Western educational scholarship imported in China during the past century, 'philosophy of education' was firstly received in 1917 among other 44 imported disciplinary studies on education (p. 29). Since then, 'philosophy of education' in China has undergone over a 100 years journey, during which not only great Western educators, such as Comenius and Pestalozzi, Herbart and Dewey, Humbodt and Freire, ${ }^{3}$ have been well familiarised, but so also have influential educational thoughts e.g., Experimentelle Pädagogik (Experimental Pedagogy), Kulturpädagogik (about Bildung), Progressivism, Perennialism, Essentialism, and Reconstructionism. ${ }^{4}$ In the centurial reflection, the Chinese academic community, in particular the Chinese society of philosophy of education has been becoming increasingly concerned with (1) indigenous theories, which would suit modern China particularly while are not necessarily parochial; (2) theories in effective relations to the frontline practice (Yu and Qin 2009; Hou 2011; Shi 2014). While emphasising the indigenousness and the effectiveness of theory, it does not mean the value of the ongoing study from counterparts in the West has been undermined. Rather, a good understanding of Western (though mostly Euro-American) philosophy of education has always been strengthened, especially those critical events and peak experiences. With such a Chinese learning concern, I therefore intend to delve into two valuable

\footnotetext{
1 https://journals.sagepub.com/home/roe, accessed on 24 April 2019.

2 https://brill.com/view/journals/bire/bire-overview.xml, accessed on 24 April 2019.

3 This grouping and nomination is to signify the apparent contribution to establishing elementary education, secondary schooling, higher education and adult education. For a related thought, see Tröhler (2013, p. 52).

4 The thoughts mentioned are illustrative and not exhaustive.
} 
traditions of critique-both contemporaneous and complementary-in Western philosophy of education spanning the 1960s to the 1980s: the practical theory of education in the Anglophone tradition and the critical theory of education in the Continental world.

In what follows, I will introduce the two critical models of philosophic educational theory - namely, analytic practical educational theory and German Critical Pädagogik-one after another by focusing on their complementary differences. That is, in Section I and Section II, contrasts between their characteristic rationalities, their typical forms of criticism and the corresponding ways to be deployed in critique, as well as their frames of reference regarding the sources of their criticalities, will be respectively examined. For a summary of simplified points of comparison and contrast see Table 1 (Appendix) attached. Finally, in Section III, I will argue for their intrinsic value, practical value, and epistemic value when they are put in juxtaposition. In particular, the distinctiveness and the complementary quality that they encompass add vitally to the understanding of Western construction of educational knowledge which is divided into two camps: one the foundational and the other the autonomous.

\section{The Analytic Practical Theory of Education}

Basically, the clarification of educational theory as a practical ${ }^{5}$ one is a significant contemporary contribution coming from the analytic philosophy of education since the 1960s. While Hirst (1966) argues systematically for a conception of educational theory as practical theory, Moore (1974) later externalises that idea comprehensibly in his monograph titled Educational Theory: An Introduction. For them, education is primarily a practical enterprise-getting things done in this world, changing the attitudes and behaviors of people, usually those of children, and thus educational theory's function is prescriptive, telling what we should do supported by reasons. Overall, for an analytic conception of practical theory of education, it is chiefly concerned with the rational justification-the rational examination in an item-by-item fashion. Part and parcel this is influenced by the then dominant analytical philosophy which is typically against ways that prefer to conceptualise the totality of a given field and then to go immediately to develop encompassing theories.

According to Moore (1974, p. 16, p. 84, p. 94), the structure of practical theory begins with assumptions about ends to be achieved and materials to be worked on and, concludes with recommendations that certain things should be done. Thereby, educational theory which is practical would be formulated in the following form, though simplified:

1. $\quad \mathrm{P}$ is desirable as an end (assumptions about what is to be achieved)

2. In the circumstances, $Q$ is the most effective way of achieving P. (Q would be broken down into an indefinite number of pedagogical activities)

3. Therefore, do whatever Q involves (the actual methods recommended).

\footnotetext{
5 To designate the analytical model of education as practical will cause confusions, since the German critical pädagogik as discussed below is more complied with our understanding of 'being practical in actions'. However, it is a historical fact that when analytical philosophers of education in the 1960s defended the possibility and necessity of educational theory, they argued the nature of educational theory as practical. Thus, the coinage of analytic practical theory of education herein arises from that historical debate. Overall, if we follow this historical term and focus on its critical dimension, confusions will then be dissolved.
} 


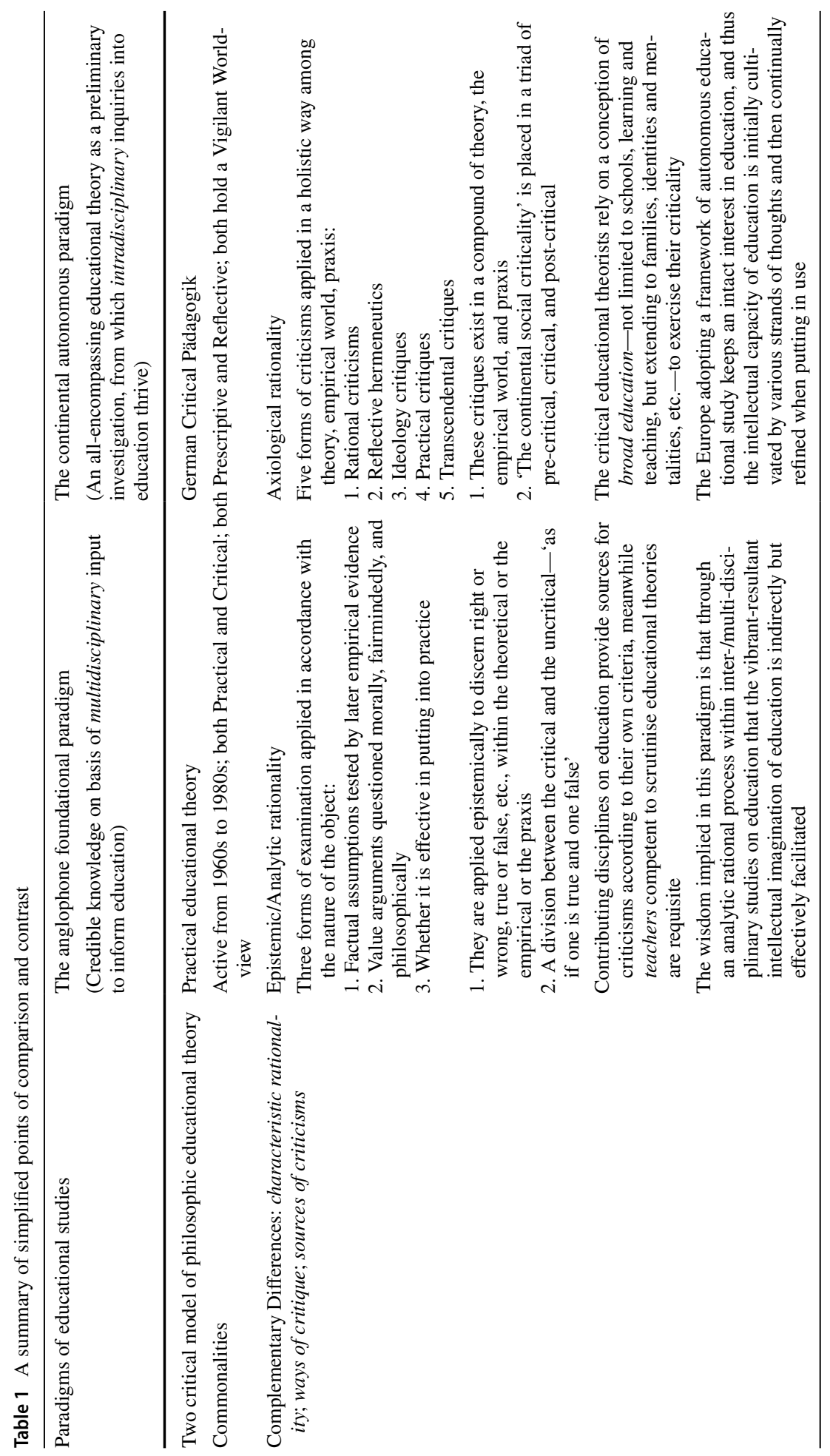


That is, the contents to be filled in this structure are assumptions or arguments about aims of education, nature of the children and knowledge, as well as conclusions for what is recommended for practice. ${ }^{6}$ Taken in conjunction with some declared aims, different assumptions about children and about knowledge and methods (Moore 1974, pp. 20-21 and pp. 84-97), approximately three prototypes of practical educational theory as a result can be identified. These three types are the traditional approach, the child-centered or progressive approach, and a third one which Moore called 'a contemporary model' essentially conforming to the analytic ideals of educated persons, ${ }^{7}$ of worthwhile knowledge, as well as of permitted pupil participation (for the point of participation, also sees Peters' minimal criterion of wittingness and voluntariness, 1965, 1966).

Admittedly, there are some assumptions and pronouncements assumed in this model of practical theory which are not empirically testable for they are beyond capacity now and even in a conceivable future. Additionally, there are some meta-assumptions, which might be just beyond human thinking: e.g., 'assumptions about the uniformity of nature and universal causation' as commonly presupposed with scientific theories (Moore 1974, p. 15), or meta-postulations that are particularly held by educational theories-such as 'the plasticity of human behavior' (Moore 1974, p. 18). Nevertheless, the practical theory of education is capable of being validated in its own terms, given that it is reasonably defensible-be possible to be criticised and able to stand up such criticisms.

Illustrated by Moore (1974), there are at least three sorts of criticisms we can apply. First, factual assumptions contained in the practical theory of education are open to criticisms based on later empirical evidence. It is amenable in light of subsequent and up-todate accessions of knowledge provided by latest scientific study of what the world is like, and especially that part of world related to the nature of children, their development, the way they learn and the way they react to social influences (p. 11). Secondly, value assumptions, conclusions and arguments of the practical theory of education could be questioned by appealing to criteria of a moral or philosophical kind. In this aspect, we can ask this series of questions: whether it is morally acceptable or not, over-emphasise the importance of one thing or not, consistent/coherent with other parts of the discourse or not (p. 48, p. 62). At a third point, we can validate it by the yardstick of 'being practical' itself, which is to check whether it is effective in putting into practice (p. 17). Undoubtedly it is controversial that a theory is deemed to be vulnerable just because it is not realistic enough. But the point here is not to reject valuable idealistic aims which legitimately await to be realised, but object to a theory as unrealistic for ignoring objective basis of human conditions (e.g., the material/technical limit, the physical/psychological restraint). To illustrate, we should give up the 'non-practical' theory which pursues children to learn all happily and easily, for it is nothing more than an unachievable, and at worst, unwholesome utopia.

Regarding the resources that we derive to develop criticisms or justify principles as anticipated in the analytic model, the conceived status and scope of educational theory is relevant. In the Anglophone configuration of academic educational studies, mainly because

\footnotetext{
6 The analytic practical theory of education, in terms of its content and structure, is to some extent commeasurable with theory of Erziehung in the German academic study of education (which is usually concerned with the following three aspects: aimed influences, processes or means, and objects that aim to be educated, see Biesta 2011, pp. 183-184). However, the analytic style of examination on these components is developed through the application of the second-order analysis which offers its own irreplaceable contribution.

${ }^{7}$ For a relatively comprehensive defence of this concept against criticisms from conservatism, elitism, feminism, multiculturalism, see Scheffler (1995).
} 
of a historical background of preparing professional teachers at the contemporary university level (with credible knowledge), the development of educational theory was construed in an inter-/multi-disciplinary form and specifically directed to school education (for a theoretical clarification, see Hirst 1990, pp. 77-85; for a detailed social-historical account, see Biesta 2011, pp. 177-183). Since the logic of groundwork of educational theory implies that the justifications of principles (which are to guide educational practice) rely on theoretical inputs from fundamental disciplines, specialised studies of education are then expected to function as providing reasons to inform principles or to carry out criticisms. What is significant in this framework is that, each of the contributory disciplines provides its own internal autonomous criteria about what evidence is relevant, what test is of truth or falsehood, etc. (Hirst 1966, p. 51; Moore 1974, p. 68). Another crucial proviso is that the critical role that teachers play becomes an indispensable part of this intellectual consolidation. This is because the practical theory of education does not follow from a theoretical synthesis among various disciplinary inquiries into education, but a form of judgments based on as comprehensive a view of the issues as it is possible to get (see Hirst 1966, pp. 35-36, p. 54; Moore 1974, pp. 95-96). That is, the teacher-he/she must be his/her own general theorist of education. It is also because practical theories of education will be an on-going concern, changing in content as circumstances require (Moore 1974, p. 95), and at each step there will be room for hesitation, dispute and readjustment (p. 98). Thus, the teacher is expected to employ the broad conclusions of those who have done the contributing work, to use research for his/her own ends in education (Moore 1974, p. 68). Briefly, contributing disciplinaries about education provides sources in accordance with their own criteria for subsequent justifications and criticisms, meanwhile teachers who can exercise the three forms of disciplined scrutiny as depicted in the forgoing account are vitally necessary.

To sum up, the analytic practical model is characterised with an epistemic-oriented criticality and professional participants at work. In particular, teachers are expected to be competent in rational examinations of educational theories, especially in examining factual and value information, in judging whether it is desirable and practical on the human condition. Furthermore, this model situates in a paradigm of inter-/multi-disciplinary educational studies and, pursues clear and rigorous understandings by breaking things down and supplanting faulty arguments and hasty generalisations. The wisdom implied in this model is that through such an analytic rational process, the subtle intellectual unconsciousness assumed in educational theorising is vibrantly revealed.

\section{The German Critical Pädagogik}

The critical theory of education that we focus on was developed in Germany from the 1960s to the 1980s (Peng 2002, p. 52; Masschelein 2004, p. 352; Biesta 2005, pp. 143-145), the same time period when the model of practical educational theory was prominent in the Anglo-Saxon world. ${ }^{8}$ Certainly, in many other aspects they have similarities, such as achieving human freedom composed of self-determined individuals and a common vigilant

\footnotetext{
${ }^{8}$ In this paper shedding light on to the German critical pädagogik, in comparison with the analytic-practical approach spanning the periods from 1960s to 1980s, it does not mean there were no other strands of educational thought. For example, pedagogy as a hermeneutic science (geisteswissenschaftliche Pädagogik) still exercised its influence, though generally on the wane. In addition, for the diversity of the field after the 1980s, see Standish (2004).
} 
attitude towards the outside world (i.e., a shared worldview that things are not what they look like). Even the key terms of 'practical' and 'critical' as characterising each of them are interchangeable - the German critical theory of education complies with the criteria of practical theory as set in the above analytic conception, since its key issue in criticising the authoritarian structure within schools for a real society of equality and democracy (Chang 2008, p. 131) is essentially of praxis. Likewise, the analytic practical theory of education inclined towards a rational examination is no doubt of critical style, and thus a rationalistic sort of critical theory of education. However, the main reason to put them in parallel is not because of their commonalities, but more owing to their distinctive yet complementary roles in typifying criticalities, rationalities, and practicalities. Hence, in this paper the aspects of their significant difference will be focused. By consulting related literature published in Chinese or in English, ${ }^{9}$ I will try to present an account of the German critical pädagogik in contrast with the analytic clarification of practical theory of education.

First, compared with the analysts' passionate inspiration to a higher level of intellectual rigor, the German critical pedagogues' primary concern is rather axiological and thereby practical in actions. It aims at the prevention of Auschwitz and the deconstruction of authoritarian culture in the post-WWII German society, and at a further step the emancipation of the individual and the society by individual criticality exercised towards the existing social order (Lenzen 1997, p. 4; Heyting and Winch 2004, p. 315; Biesta 2005, p. 143; Chang 2008, p. 131; Winkler 2017, p. 69). ${ }^{10}$ The emphasis of the German critical pädagogik on the social and political context also has its origin within the German pedagogy tradition. In the 1960 s, critical pädagogik by exercising its social-axiological critique played a role in resisting the then dominant ideas of pedagogy as a hermeneutic science (geisteswissenschaftliche pädagogik) which over-emphasised individual-internalised understanding and as the positivism in educational research which was indulged into casual relationships (Chang 2008, pp. 135-139; Liang 2010, p. 962; Tröhler 2013, p. 59; Winkler 2017 , pp. 69-70). Eventually, the legitimate place of value is not only recognised in educational inquiries by the efforts of the critical pedagogues, but also the critique and examination of those imbedded values are also ensured. ${ }^{11}$

Whereas the analytic practical theory asks questions about epistemic adequacy, the German critical pädagogik is directly preoccupied with its value critique e.g., questions of social justice and emancipation. That is, the German critical model exercises axiological critique, investigating power relationship in institutional and societal level, and addressing significant larger issues such as the hidden interest, the constructed epistemology and the real effect in practice. Further, in comparison with the analytic rationality of the practical model, the characteristic rationality exemplified by the continental critical model is a sort of axiological rationality. When dubbed 'analytic rationality', it does not mean all about logical and conceptual scrutiny and nothing about discussions of value, as we can see in the analytic practical model moral evaluation is involved as one part of its criticisms. By the same token, when exemplifying the axiological rationality, as the critical pedagogues always ask, 'Who benefit?', 'Is what is implemented really educational?' and

\footnotetext{
9 These works are written by scholars who can access German, besides their commands of either/both Chinese or/and English.

10 Professor Winkler's academic presentation in English—'the Concept of Critical Pedagogy' — was at first delivered at National Chung Cheng University, Taiwan, in 2008, and recently it has been translated and published into Chinese, see Winkler (2017).

11 I owe this point particularly to Cheng $(2016$, p. 6).
} 
assume a stance of 'not to be deceived by the hidden', it does not mean examination of factual information can be excluded. Fairly speaking, the analytic rationality and the axiological rationality are both indispensable parts for each; it is a matter about 'ratio' - while the practical theory of education prioritises the former and the critical theory of education is more associated with the latter.

As a second point about the concrete forms of criticism that the critical pedagogues adopt, it consists generally of five ways (see Benner's categorisations, 1999, pp. 38-41) ${ }^{12}$ :

1. Rational criticism (the representative thinker is Karl Popper);

2. Reflective hermeneutics (to explain the existing prejudices and aim at reconstruction);

3. Ideology critique (on basis of hermeneutic reflection with a further step to seek alternatives);

4. Practical critique (the object of critique to be extended to what Benner categorises into the other five forms of practice-i.e., economics, politics, art, morality, religiontogether with the educational realm, they are constitutive of human life);

5. Transcendental critique (a critique of the above four forms which reminds what is beyond human thinking and meanwhile cannot be simply believed in).

However, alongside the three sorts of criticism purposed by the analytic practical theory, the crux is not how many categories we have successfully identified but how we conceive the relationships among them, as revealed by the German critical lens. It is very interesting that the relationships among these five sorts of criticism in the German critical exercise is neither selective nor of complementary synthesis, as suggested by Benner (1999, p. 42). Instead of the monopolisation of one form of critique, 'a pluralization of critique that interchangeably applies the competing approaches [of critique] to each other' is implied (Benner and English 2004, p. 421). Put another way, these critiques are placed in a triad of pre-critical, critical and post-critical tension, rather than a dichotomy between critical and the uncritical (see Benner and English 2004, p. 422). It is thus obviously different from the three sorts of examination in the analytic practical model, which are applied selectively in accordance with the nature of the object examined, e.g., differentiating the factual from the evaluative. Let alone a differentiation between the critical and the uncritical (e.g., right from wrong and true from false) for the sake of basic epistemic clarity that is acclaimed in the analytic practical model of critique. Further, for the German critical pädagogik, the criticality exists in the relationships among theory, empirical world, and praxis where the above five forms of criticism are accommodated and function in a holistic (three-dimensional) way. Put alternatively, it is to connect rather general ideals and insights with concrete, empirical facts and observations in a given educational situation (Winkler 2017, p. 64), in which five forms of criticism could work organically and criticise powerfully.

Related to such a holistic criticality, the question of sources of criticism, which sustains this particular theoretical configuration, also attends. While in the Anglophone tradition the inter-/multi-disciplinary approach provides resources for justifications and the critical competence of the teacher is concomitantly requisite, critical educational theorists in the European tradition rely on a vantage point to diagnose and to

\footnotetext{
12 It is interesting to contrast Benner's fives ways of criticism with Burbules' (1992) five forms of ideologycritique: (1) rational critique; (2) immanent critique; (3) deconstrutionist-which denies the existence of an objective truth (see related arguments in a different context by Shu 2014a, b); (4) an argument from effects; (5) with a counter-ideology.
} 
reveal the problems and shortcomings which prevent the realisation of liberty (Masschelein 2004, p. 355). Regarding such privileged attitudes or higher values, Winkler (2017, pp. 66-69) identifies ten roots in the German critical pädagogik which cultivate the intellectual vitality to critique. Winkler's list is not intended to be exhaustive, but it is worth to relisted here as illustrations of the prominent foundations of the German critical tradition: (1) Thomas Morus' (1478-1535) and Tommaso Campanella's (1568-1639) optimism and utopia on betterment of the world; (2) the early humanism on human dignity; (3) capitalists' ideal of personal autonomy; (4) Enlightenment rationality; (5) Democracy; (6) Bildung (the subjective and objective relationships among individual, society and culture); (7) romantic philosophy; (8) a strong connection between morality and aesthetics; (9) the early writings of Marx and the critics of political economy; (10) psychologists', such as Jean Piaget's and Lev Vygotsky's theories on the interaction of human brain and outer experiences. Additionally, the most visible source could be related to the more recent Frankfurt school-thinkers like T.W. Adorno and J. Habermas (Peng 2002, p. 52; Masschelein 2004, p. 353; Biesta 2011, p. 187; Tröhler 2013, p. 59). In short, the critical educational theorists in the German paradigm rely on a conception of education which is initially cultivated by various strands of thought such as listed above, forming a base for further exercise of their criticality (Winkler 2017, p. 64; Biesta 2011, p. 190). This is in contrast with the analytic understanding of education, which is resultant and generated throughout rational procedures and examinations by applying multi/inter-disciplinary studies.

Certainly, this uniqueness of framing sources of criticism in the German critical theory of education is inseparable from its wider configuration of academic educational study in the European tradition. As the Europe emanates an apparent independence of educational study by its association with the relative autonomy of educational practice (Biesta 2011, p. 187; Tröhler 2013, pp. 51-52), the autonomous educational study works on its own forms of theorising and conceptual structures (see the Continental various versions of 'General Pedagogy'). Just as Hordern (2018, p. 589) further explains, it is '[such] a distinct disciplinary tradition of specifically educational thought [i.e., in the Germany] powered by educational concepts that can have resonance in practice'. Thus, while the analytic practical theory derives reasons from interdisciplinary studies-first using scientific or reflective theories of fundamental disciplines to justify, and then relying on professional teachers' comprehensive understanding of theories to act in education, the German critical theorists situate within an intra-disciplinary design to address education more directly.

All in all, the German critical theory of education in the Continental-European educational scholarship manifest its criticality towards education in a holistic and axiological way, emphatically analysing the relation at a given historical stage between individual subjects and societies, and cultures. Compared with the Anglophone-Analytic paradigm, the continental critical model is associated with the educational inquiry as an independent field while is not necessarily detached from other studies related to education. Furthermore, the distinctiveness of the Anglophone tradition and of the European tradition can also be seen through the writing styles of their scholars. For instance, if the work by Burbules (1992) is juxtaposed with that by Benner (1999), even translated in a third language, say Chinese, the difference is vivid-in the sense that discussing the same topic how the Anglophone scholar writes with a high level of clarity, while the European scholar writes at a macroscopically inspiring way. 


\section{Three Contributing Points of Comparing and Contrasting the Two Critical Models}

There are three contributing points that can be made explicit when the two contrasting critical models are put in juxtaposition. First, it is concerned with the immanent value of coexistence - each one a kind of worthwhile critique on its own terms, and most importantly when put together they are complementary. Secondly, it is about their practical value in exemplifying the unique construction of academic educational studies, which has respectively developed in the Anglo-American world (mainly the UK and the USA) and in the European world (Germany, Belgium, Finland, Spain, the Netherlands, etc.). Thirdly, alongside other equivalent knowledge-achievements accomplished in the two main convincing paradigms of educational studies in the West, the two critical contributions can be counted as peak scholarly experiences. Consistent with the accounts developed in Section I and II, I will continue to draw upon relevant, existing research literature to develop my arguments. This also includes some related observations coming from and analyses made by contemporary Chinese educational scholars.

\section{The Value of Being Complementary When the Two Self-legitimated Models are Put in Parallel}

Burbules and Berk (1999, pp. 58-59) argue for the benefit of the coexistence of both Critical Thinking and Critical Pedagogy in terms of the sustained difference-intellectual vitality that they yield while made in juxtaposition. Certainly, Critical Thinking and Critical Pedagogy in Burbules and Berk's context do not wholly equal to the practical and the critical model in this paper. Since Burbules and Berk's work concerns with a period between the 1980s and the 2000s, while here it relates to two decades before the 1980s. However, there are indeed similarities in arguing for coexistence.

First, this owes to the similar orientation shared both by the practical educational theory and Critical Thinking; that is, both of them are concerned characteristically with epistemic adequacy, e.g., valid argument, supporting evidence, and conceptual clarity. As Oancea and Bridges (2009, p. 556) summarise, this analytic rationality aims at differentiating the logical from the rhetorical, the normative from the factual, tautology from circularity, and correlation from causality, meanwhile pays particular attention to examine if there are category mistakes or counter arguments. Doubtless, the practical model is thus one kind of worthwhile critique on these terms. On the other hand, since the critical pädagogik characterises itself by discerning the particular ways that undue power exercises in institutional and societal levels, the normative rationality that it encompasses is complementary to the practical model's epistemic criticality.

Secondly, as both models of educational theory are concerned with right ways to do in concrete practices, there is another form of being complementary. That is, their practicalities are supplementary to each other. Whereas the understanding of 'being right' interpreted by the analytic-practical model is primarily centred on justification (in thinking), on the part of the continental-critical model it is mostly around justice (in action). Further, whilst the German model places its holistic criticism among a realistic triad of theory, empirical world, and praxis, the analytic tradition emphasises the critical function performed by the most important educational practitioners - teachers-as an indispensable part. The last but not the least, the explicit division between the critical and the uncritical 
as implied in the analytic-practical paradigm is regarded as elementary, in comparison with more complicated tensions among the pre-critical, the critical and the post-critical intended in the German tradition.

Taken together, the practical and critical theories of education as depicted are inter-sustaining. On the one hand, both of them share the very same consideration of 'being critical' towards education either in theory or in practice, aiming at 'overcoming ignorance' and 'discerning distortions'. On the other hand, with the same aim but complementary approaches-different priority of the epistemic and the axiological; different emphasis on the realistic structure and the frontline practitioners - the two can beneficially add to each other when facing common challenges (e.g., the postmodern accusation of the deficiency of rationality) or realising the shared ambition (i.e., human emancipation). Hence, it is obvious that both the practical theory and the critical theory have their own legitimate value in exercising criticality and practicality. Significantly, while placed in parallel, their distinctiveness with excellent complementary traits makes them invaluable for the training and the teaching of Western Philosophy of Education as a discipline. This is a reason to call them peak academic experiences which I will further explain.

\section{The Value of Manifesting the Uniqueness of Construction of Educational Scholarship Between the Anglo-American and the European}

Biesta (2011) has already depicted in a way of macro-comparison the difference of the academic configuration of education in the English-speaking world and the European world. On the other hand, for the Chinese, the West mainly refers to the Continental-European and the Anglo-American tradition, it is thus important to realise the subtle differences/relations between the two regions, if the Chinese aim to have a good understanding of, and a good learning from, what they think as the West. Hence, the juxtaposition of the practical and the critical theory of education from the 1960s to the 1980s cannot be better to serve as befitting examples to illustrate.

Even though Hirst (1983, p. 20, 1990, pp. 79-83) in his later turn made a transition from the epistemic priority to the pragmatic process where he saw educational theory as the justification of technically and ethically successful practices (rather than explicit justifications of principles) in education, the significant distinction between the two cannot be denied. This is mainly because the analytic (practical) paradigm's insistence on 'means of the relevant contributory disciplines' (Hirst 1983, p. 21, 1990, pp. 82-86) is consistent, while it is not an explicit concern for the German (critical) paradigm. Briefly, that the two models can be seen as miniatures of their respective educational tradition of the Anglo-American and the European lies in their unique framing of sources of criticism and their different ways to deploy corresponding forms of criticism.

As the English-speaking world holds the inter-/multi-disciplinary studies on education, contributory disciplines provide reasons and evidence for criticisms according to their own criteria; meanwhile teachers competent to scrutinise educational theories are requisite. By contrast, as the German-speaking world sees educational inquiry as a field of study on its own, the German critical pädagogik is unavoidably based on the chief-discipline 'Gerneral Pedagogy' (e.g., including central discussions on the constitutive elements of the soul/subjectivity/humanity, see Tröhler 2013, p. 54). It is thus to develop an initial conception of education, and then is enabled to exercise its criticality holistically among theory, empirical world, and praxis. The wisdom implied in the European tradition is that while keeping an intact interest in education, the intellectual capacity is initially cultivated by various 
strands of thought and then continually and effectively refined when being used. Since the Anglophone region intends an analytic rational process situated within inter-/multi-disciplinary studies on education, its advantage lies in that, the educational intellectual capacity (notably the understanding of education) as a result, is to be indirectly and rigorously fostered. Thus, for the Chinese or others who wish to better learn from the West, the two in juxtaposition could serve the purpose of exemplifying the uniqueness of educationalintellectual tradition located in the Anglo-American and the European world. In particular, the different critical sources that the two models of philosophic educational theory rely on demonstrate how the former is situated in a basic-applied construction of educational studies while the latter is located in a construction of autonomous educational inquiry.

Indeed, there are also striking contrasts within the European world itself, e.g., the contrast between two main European countries-Germany and France-in their intellectual and institutional development of educational scholarship is, to some extent, akin to what we have discussed here the contrast of that between the Anglo-American and the European (see Schriewer and Keiner 1992), and it is indeed worthwhile to investigate further the plurality within continental Europe. Nevertheless, in this paper suffice it to say-the analytic practical model and the German critical pädagogik each successfully demonstrates undeniable and significant characteristics of philosophic educational inquiries respectively developed in the Anglo-American world and the European land.

\section{The Value of Strengthening the Establishment of the Two Main Convincing Paradigms of the Configuration of Educational Studies}

The primary aim of this paper is to make distinctions, generating a way of understanding of the two traditions of educational studies in relation to a philosophical-critical dimension. It aims ultimately for a well-argued account of the richness of the two paradigms of educational studies - basically the Anglophone foundational paradigm and the Continental autonomous paradigm. The author does not deny the potential dangers, when these distinctions made in such a contrasting way, of generalising the analytic approach to the Anglophone paradigm and reducing the Continental paradigm into the critical approach. What is more, it is certain that the two models of criticality are not entirely separate from each other and thus the difference cannot be overemphasised. Furthermore, recurring to a previous point, when Hirst (1983) later turned to social and contextual aspects, a convergence between the two sorts of philosophic educational theories even emerged.

However, to attend to such dangers of misunderstanding while not forsaking the aim of achieving a fine-grained analysis of the two academic constructions of educational studies, the author invites readers to situate this piece of study into a holistic picture of comparison and contrast between the two paradigms of educational studies. That is, apart from this critical dimension, other equivalent dimensions involve the teaching and learning (Anglophone Curriculum Studies VS German Didaktik) (see Gundem and Hopmann 1998; Friesen 2018), the aim(s) of education (Growth VS Blidung) (see Siljander, Kivelä and Sutinen 2012), the conception of education (three criteria of education by R. S. Peters who is one of the fathers of the Anglo-Saxon construction VS the time-honoured pedagogical triangle held in the continental European configuration).

In contemporary China, scholars in education use 'the educational study in a singular term 单数教育科学' and 'the educational sciences in a plural term 复数教育科学' (e.g., see Yang 2019) to characterise the difference of the two main camps of educational scholarships. A well-established scholar Guisheng Chen (陈桂生) from 2018 to 2019 has 
published four journal articles to address cultural differences in constructing educational studies and research (Chen 2018, 2019a, b, c; also see Cheng 2016). In Chen's account, reflections on educational studies of a Soviet Union lineage are also included. In addition to these pure theoretical understanding, it is also observable that among the educational practices led by top Chinese educational scholars, there exist two ways of carrying out their enterprises following the logic either of the Anglo-Saxon or of the continental European educational scholarship. For example, Professor Lan Ye (叶澜)'s cluster on 'life-practice pedagogy' (生命.教育学派) works within the European paradigm. Not only from their working title using the term 'pedagogy' that we can tell their scholarship base, but also from their emphasis on the autonomy of the discipline of educational study (Ye 2009). Only in terms of the European paradigm, that the autonomous presupposition-education as a discipline in a singular term—is a vital rationale. By contrast, Professor Wei Yu (于 伟)'s cluster on 'children's philosophy and free-spirited education' (儿童哲学与率性教育) can be categorised as a practice aligned with the foundational paradigm. This is because in examining works from Yu's cluster the autonomous status of educational studies is not explicit while a focus on the study of children's philosophy and the application of it into teaching and learning that is the crux for them (see Yu et al. 2018).

Frankly speaking, just as the understanding of the distinction between the two main convincing paradigms of the configuration of educational studies is not yet clear and systematic in the West, such understanding is neither absolutely conscious in the Chinese community. Let alone applying this understanding to analyse the generation of educational knowledge. However, scholars do start to search for a fine-grained account of comparison and contrast between the two paradigms, besides the Biesta 2011 paper and the work done in China, also see Westbury, Hopmann, and Riquarts (2000). In particular, Westbury in his Chapter 1 of the same book systematically analyse the characteristics and the differences between 'Didaktik' and 'Curriculum'. He explains how the Anglophone paradigm and the European paradigm deal with the similar questions of teaching, learning, teacher education in different ways.

Admittedly, it is not easy at the moment to find many examined examples to illustrate the existence and necessity of the coexistence of two sensible paradigms of educational studies. Otherwise, our understanding and knowledge of the two camps of educational scholarship would be much more advanced. Nevertheless, the exploration by Westbury et al. (2000) of a teaching and learning dimension is persuasive, demonstrating that there are indeed two systems, and each can learn from each other. Such an analysis on 'Didaktik' and 'Curriculum' counts a piece of peak experiences in educational scholarship, because it sustains and develops, and thereby constitutes a detailed understanding of the contents of the two paradigms of educational studies. In addition, they are accessible, classical presentations of the establishments accumulated in the two traditions to serve professional training and teaching purposes. In these terms, the analytic practical educational theory and the German critical pädagogik counts as another piece of peak experiences. Briefly, it is because they successfully illustrate how the two systems manifest the same critical dimension into two different self-legitimated forms which are at the same time inter-sustaining.

Acknowledgements With special thanks to professor Cheng-Hsi Chien 簡成熙, professor Yanjie Chi 迟艳 杰, and Dr. Karsten Kenklies, for their helpful suggestions and feedback. Of course, I on my own shall be responsible for my paper. 


\section{Compliance with Ethical Standards}

Conflict of interest The author declare no conflict of interest.

Open Access This article is distributed under the terms of the Creative Commons Attribution 4.0 International License (http://creativecommons.org/licenses/by/4.0/), which permits unrestricted use, distribution, and reproduction in any medium, provided you give appropriate credit to the original author(s) and the source, provide a link to the Creative Commons license, and indicate if changes were made.

\section{Appendix}

See Table 1.

\section{References}

Benner, D. 1999. On the relationship between education and critique and the limitations of various sorts of Critical Pedagogies [教育学与批判一对各种批判教育科学思想的局限性及问题关系的思考]. (Trans by Q.L. Li and Z.M. Peng). Journal of East China Normal University (Education Sciences) [华 东师范大学学报(教育科学版)] 2: 31-43.

Benner, D., and A. English. 2004. Critique and negativity: Towards the pluralisation of critique in educational practice, theory and research. Journal of Philosophy of Education 38: 409-428. https://doi.org/1 0.1111/j.0309-8249.2004.00394.x.

Biesta, G. 2005. What can critical pedagogy learn from postmodernism? Further reflections on the impossible future of critical pedagogy. In Critical theory and critical pedagogy today: Toward a new critical language in education, ed. I. Gur-Ze'ev. Haifa: University of Haifa, Faculty of Education.

Biesta, G. 2011. Disciplines and theory in the academic study of education: A comparative analysis of the Anglo-American and Continental construction of the field. Pedagogy, Culture \& Society 19(2): 175-192.

Burbules, N.C. 1992. Forms of ideology-critique: A pedagogical perspective. Qualitative Studies in Education 5(1): 7-17.

Burbules, N.C., and R. Berk. 1999. Critical thinking and critical pedagogy: Relations, differences, and limits. In Critical theories in education: Changing terrains of knowledge and politics, ed. T. Popkewitz and L. Fendler. London: Routledge.

Chang, S.M. 張淑媚 2008. On K. Mollenhauer's (1928-1998) Critical Pedagogy [評析德國教育學者 K. Mollenhauer (1928-1998) 的批判教育學思想]. Taiwan Journal of Sociology of Education [臺灣教育 社會學硎究] 8(1): 129-150.

Chen, G.S. 陈桂生 2018. What exactly is pedagogy: A discussion on the basic concept of pedagogy [教 育学究竟是怎么一回事——教育学基本概念问题]. Journal of Educational Studies [教育学报] 1: 3-12.

Chen, G.S. 2019a. The second discussion on 'What exactly is pedagogy': Problems solved and problems await to be solved [再论教育学究竟是怎么一回事—教育学研究中遇到的已经解决与待解决的 问题]. Education Sciences in China [中国教育科学] 2: 20-37.

Chen, G.S. 2019b. The third response to 'What exactly is pedagogy': The crux of the localization of western pedagogy [教育学“西学中化”问题的症结—三谈教育学究竟是怎么一回事]. Journal of Educational Studies [教育学报] 3: 3-9.

Chen, G.S. 2019c. Comparison of Chinese and western educational cultures: The fourth discussion on “What Exactly is Pedagogy” [中西教育文化比较—四谈教育学究竟是怎么一回事]. Global Education [全球教育展望] 8: 29-36.

Cheng, L. 程亮 2016. Plural traditions and their emergent interactions-A cross-cultural study on knowledge construction in pedagogy among countries of Germany, United Kingdom, United States, and China [多元的传统与交互的生成一一教育学知识建构的跨文化比较]. Educational Research [教 育㸴究] 5: 4-13.

ECNU. 2017. Manifesto of the positivist educational research. http://news.ecnu.edu.cn/58/98/c1833a88216/ page.htm. Accessed 29 Dec 2017. 
Friesen, N. 2018. Continuing the dialogue: Curriculum, Didaktik and theories of knowledge. Journal of Curriculum Studies 50(6): 724-732.

Gundem, B.B., and S. Hopmann. 1998. Didaktik and/or curriculum. An international dialogue. New York: Peter Lang.

Heyting, F., and C. Winch. 2004. The role of critique in philosophy of education: Its subject matter and its ambiguities. Journal of Philosophy of Education 38(3): 311-321.

Lenzen, D. 1997. Educational science in Germany: Theories-crises-present situation. In Educational studies in Europe: Amsterdam and Berlin compared, vol. 1, ed. F. Heyting, J. Koppen, D. Lenzen, and F. Thiel. New York: Berghahn Books.

Hirst, P.H. 1966. Educational theory. In The study of education, ed. J.W. Tibble. London: Routledge \& K. Paul.

Hirst, P.H. 1983. Educational theory and its foundational disciplines. London: RKP.

Hirst, P.H. 1990. The theory-practice relationship in teacher training. In Partnership in initial teacher training, ed. M.B. Booth, V.J. Furlong, and M. Wilkin. London: Cassell Educational Ltd.

Hordern, J. 2018. Educational knowledge: Traditions of inquiry, specialisation and practice. Pedagogy, Culture \& Society 26(4): 1-15.

Horlacher, R. 2015. The educated subject and the German concept of Bildung: A comparative cultural history, vol. 2. New York: Routledge.

Hou, H.Y. 侯怀银 2011. Western educational scholarship at 20th centurial china: Its transmission and influence [西方教育学在20世纪中国的传播和影响]. Changchun: Northeast Normal University Press.

Liang, F.C. 梁福镇 2010. Inquiry into Dieterich Benner's normative pedagogy [邊納爾規範教育學之探 究]. EurAmerica [歐美㸴究] 40(4): 947-983.

Masschelein, J. 2004. How to conceive of critical educational theory today? Journal of Philosophy of Education 38(3): 351-367.

Ministry of Education of the People's Republic of China. 2011. Document Teacher [2011]6. http://old.moe. gov.cn//publicfiles/business/htmlfiles/moe/s3702/201110/xxgk_125722.html. Accessed 30 Dec 2017.

Moore, T.W. 1974. Educational theory: An introduction. London: Routledge \& Kegan Paul.

Oancea, A., and D. Bridges. 2009. Philosophy of education in the UK: The historical and contemporary tradition. Oxford Review of Education 35(5): 553-568.

Peng, Z.M. 彭正梅 2002. Education of enlightenment: The German critical pedagogy study [启蒙的教 育——德国批判教育学硏究]. Global Education [全球教育展望] 31(12): 52-58.

Peters, R.S. 1965. Education as initiation. In Philosophical analysis and education, ed. R. Archambault. London: Routledge \& Kegan Paul.

Peters, R.S. 1966. Ethics and education. London: Routledge \& Kegan Paul.

Scheffler, I. 1995. The concept of the educated person. In Work, education, and leadership: Essays in the philosophy of education, ed. V.A. Howard and I. Scheffler. New York: Peter Lang Publishing.

Schriewer, J., and E. Keiner. 1992. Communication patterns and intellectual traditions in educational sciences: France and Germany. Comparative Education Review 36(1): 25-51.

Shi, Z.Y. 石中英 2014. Inaugural lecture [石中英教授就职教育哲学专业委员会主任演说], delivered at East China Normal University.

Shu, Y.M. 蘇永明 2014a. The critique of ideologies as applied educational research [意識型態批判在教育 㸴究中的運用]. In Philosophy of education: Methodologies [教育哲學:方法篇], ed. Ferng-Chyi Lin and Ren-Jin Horng. Taipei: PRO-ED Publishing Company [學富出版].

Shu, Y.M. 2014b. Deconstruction as applied in educational research [解構在教育硏究中的運用]. In Philosophy of education: Methodologies [教育哲學:方法篇], ed. Ferng-Chyi Lin and Ren-Jin Horng. Taipei: PRO-ED Publishing Company [學富出版].

Siljander, P., A. Kivelä, and A. Sutinen (eds.). 2012. Theories of Bildung and growth: Connections and controversies between continental educational thinking and American pragmatism. Berlin: Springer.

Standish, P. 2004. Europe, continental philosophy and the philosophy of education. Comparative Education 40(4): 485-501. https://doi.org/10.1080/0305006042000284493.

Tibble, J.W. (ed.). 1966. The study of education. London: Routledge \& K. Paul.

Tröhler, D. 2013. Between universally claimed theory and common understanding. In Making a difference in theory: The theory question in education and the education question in theory, ed. G. Biesta, J. Allan, and R. Edwards. New York: Routledge.

Yang, X.W. 杨小微 2019. A review on the discussions regarding the object of educational studies since 1949 [新中国教育学㸴究对象的思与辨]. Social Sciences Weekly [社会科学报]. https://mp.weixi n.qq.com/s/Y-Fn2JU7M_F1S0LdQQQgrA. Accessed 2 Nov 2019.

Ye, L. 叶澜 2009. “New Basic Education” and me. Frontiers of Education in China 4(4): 558-609. 
Yu, W. 于伟等, et al. 2018. The exploration of the theory and the practice of free-spirited education [率性 教育的理论与实践探索]. Educational Science Publishing House [教育科学出版社].

Yu, W. 于伟, and Y.Y. Qin 秦玉友. 2009. Local issues awareness and the localization of educational theory [本土问题意识与教育理论本土化]. Educational Research [教育㸴究] 6: 27-31.

Westbury, I., S. Hopmann, and K. Riquarts. (eds.). 2000. Teaching as a reflective practice: The German Didaktik tradition. Hillsdale: L. Erlbaum.

Winkler, M. 2017. The concept of critical pedagogy [批判教育学的概念]. Journal of East China Normal University (Educational Sciences) [华东师范大学学报(教育科学版)] 35(4): 62-73. https://doi. org/10.16382/j.cnki.1000-5560.2017.04.007.

Publisher's Note Springer Nature remains neutral with regard to jurisdictional claims in published maps and institutional affiliations. 